\title{
Atriyoventriküler nodal reenteran taşikardi: Patofizyolojiden tedaviye
}

\author{
Atrioventricular nodal reentry tachycardia: From pathophysiology to treatment \\ Osman Can Yontar*, İzzet Tandoğan \\ Kardiyoloji Kliniği (Dr. O. C. Yontar), Sivas Numune Hastanesi, TR-58040 Sivas, Kardiyoloji \\ Anabilim Dalı (Prof. Dr. İ. Tandoğan), Cumhuriyet Üniversitesi Tıp Fakültesi, TR-58140 Sivas
}

\section{Özet}

Supraventriküler taşikardiler; tüm yaş gruplarını etkileyebilen, yaşam kalitesini kayda değer derecede kötüleştirebilen bir hastalık grubudur. Bu grupta sınıflandırılan taşikardi tipleri arasında en sık gözleneni Atriyoventriküler Nodal Reenteran Taşikardi olarak tespit edilmiştir. Derlememizin amacı, sık gözlenen bu aritminin oluş mekanizmalarını ve tedavisini kısa ancak anlaşılır bir şekilde özetleyebilmektir.

Anahtar sözcükler: Supraventriküler taşikardi, yeniden giriş, ikili AV yolak

\begin{abstract}
Supraventricular tacycardias are a group of arrhytmias which may affect all age groups and cause remarkable recession in life quality. Atrioventricular nodal reentry tachycardia is the most common observed arrhythmia in this group. Aim of current review is to summarize the pathophysiologial basis and treatment methods in a brief and perceptible way.
\end{abstract}

Keywords: Supraventricular tachycardia, reentry, dual AV pathway

Geliş tarihi/Received: 27 Kasım 2009; Kabul tarihi/Accepted: 03 Mayıs 2012

*Iletişim adresi:

Dr. Osman Can Yontar, Kardiyoloji Kliniği, Sivas Numune Hastanesi, TR-58040 Sivas. E-posta: drcanyontar@gmail.com

\section{Giriş}

Supraventriküler taşikardiler (SVT); tüm yaş gruplarını etkileyebilen, yaşam kalitesini kayda değer derecede kötüleştirebilen bir hastalık grubudur. Genellikle eşlik eden diğer hastalığı ve yapısal kalp hastalığından yoksun kişilerde ortaya çıkarlar [1]. Amerika Birleşik Devletleri'nde yapılan bir araştırmaya göre [2] SVT insidansı 36/100.000 kişi/yıl, prevalansı ise 2,29/1000 kişidir. Buna göre sadece Amerika Birleşik Devletleri'nde; yaklaşık 570.000 SVT hastası varken bu hastalara yılda 89.000 kişinin daha eklendiği tahmin edilmektedir. SVT başlığı altında incelenen taşikardilerin prevalansı değişkenlik göstermektedir. 1991 ve 2003 yılları arasında kateter ablasyonu yapılan hastaların tarandığı bir çalışmada [3]; atriyal fibrilasyon, atriyal flutter ve uygunsuz sinüs taşikardisi dişlandığında, en sık gözlenen taşikardi \%56 sıklıkla atriyoventriküler nodal reenteran taşikardi (AVNRT), ikincisi ise \%27 sıklıkla atriyoventriküler reenteran taşikardi (AVRT) olmuştur.

\section{Tarihçe}

AVNRT, dar QRS kompleksli, düzenli taşikardinin en sık sebebidir. Bu aritminin altında yatan "reentry" (yeniden giriş) mekanizması ilk olarak 1900'lü yılların başında ortaya atılmış ve bir çok araştırmacı bunun üzerinde çalışmıştır [4, 5]. 1940 sonrasında reentry mekanizmasının atriyoventrilüer (AV) nodda yerleștiği tespit edildi [6]. İlerleyen yıllarda yapılan hayvan çalışmaları sayesinde AV nodda ikili yolak olduğu ortaya konuldu $[7,8]$. İnsanlarda yapılan elektrofiyolojik çalışmalarda, oluşturulan bazı atriyal erken vuruların His demetini depolarize etmeden, AV nod refrakter durumda iken sürekli taşikardilere neden olduğu tespit edildi [9]. 


\section{Patofizyoloji}

AV nod; Todaro tendonu, koroner sinüs ostiumu ve triküspit kapak septal yaprakçığının oluşturduğu Koch Üçgeni içinde bulunan bir yapıdır [10, 11]. AV nodun atriyal yüzeyinde görülen tranzisyonel hücreler, atryum miyokardı ile AV nod dokusu arasında sıkışmışlardır, AV nod distalinde ise His demeti içinde dallarına doğru yayılım gösteren özelleşmiş hücrelerden ve onları çevreleyen fibröz dokudan oluşmuş yolaklar bulunur [12]. AVNRT esnasında AV nodda nasıl bir mekanizmanın işbaşında olduğunu daha iyi anlamak için, "yavaş" ve "hızlı" olarak adlandılan iki yolak olduğunu varsayarak bir model oluşturabiliriz. Bu yolaklardan "yavaş" olanı, kısa süren refrakter (istirahat) dönemine sahip olup ileti hızı diğerinden daha düşüktür. "Hızlı" yolağın ise ileti hızı yüksek, fakat istirahat süreci diğerinden daha uzundur. Bu iki yolak; yapısal olarak özelleşmediklerinden histolojik incelemelerde diğer AV nod dokusundan ayrılamazlar, fonksiyonları nedeniyle ayrışmış olarak kabul edilirler [13- 15]. AVNRT'li hastalarda fizyolojik AV nodal ileti hızlı yolak üzerinden devam ettirilir. Bu iki yolağın, taşikardi esnasında antegrad (ileriye dönük) ve ya retrograd (geriye dönük) ileti yapmasına göre AVNRT iki tipe ayrılarak incelenebilir: Tipik ve atipik AVNRT. Tipik AVNRT'de, kritik zamanda ortaya çıkan bir atriyal erken vurunun "hızlı" yolağı istirahat döneminde yakalaması sonucu "yavaş" yolaktan iletilmesi ve bu esnada "hızlı" yolun istirahat sürecinden çıkması ile, iletinin hızlı yolaktan retrograd atriyuma ulaşması ile reentry halkası oluşmuş olur.

\section{Tedavi}

\section{Farmakolojik tedavi:}

Acil servise supraventriküler taşikardi nedeniyle başvuran hastalarda hemodinamik kompromizasyon olması durumunda vakit geçirilmeden kardiyoversiyon yapılması önerilir. Bununla beraber, çoğu hastada ciddi hemodinamik değişiklikler olmaz. Bu tip hastalarda vagal manevralar taşikardiyi sonlandırmak için güvenle kullanılabilir. Bu manevralar kalp üzerindeki vagal tonüsü artırıcı niteliktedir ve taşikardinin sonlanmasına ya da yavaşlamasına neden olurlar. Kardiyak parasempatomimetik etkinlik artışı, AV nod istirahat fazında geçici uzamaya neden olarak önceden söz etmiş olduğumuz ikili yolak modelinde yavaş yolağın bloke olmasına yol açar [16]. Vagal tonüsü arttırdığı bilinen manevralardan bazıları; öğürme, yüzünü soğuk suya daldırmak, valsalva manevrası ve karotis sinüs masajıdır. Bu manevralar hastalara öğretilip SVT'nin hissedildiği anda birkaç kez denemesi önerilebilir. Yaşlı hastalarda karotis masajı yapılırken karotis arter hastalı̆̆ 1 akla gelmeli ve dikkatli olunmalıdır [17]. Bu tip basit manevralar ilk planda denendikten sonra eğer taşikardi sonlanmamış ise medikal yaklaşım düşünülür. Venöz yoldan uygulanan kalsiyum kanal blokerleri (verapamil, diltiazem), beta blokerler (metoprolol, atenolol, esmolol) ve adenozin birinci basamak tedaviyi oluştururlar. Verapamil antegrad ya da retrograd yavaş yolda blok oluşturarak taşikardiyi sonlandıran etkili bir ajandır. Beta blokerler de genellikle başarıyla taşikardiyi sonlandırırlar. Ayrıca esmolol gibi etkinliği hızlı başlayan ve yarı ömrü kısa olan bir beta bloker ajanın sol ventrikül fonksiyonları yetersiz bireylerde önemi olduğunu vurgulamak gerekir. Yine bu tür hastalarda hemodinamik bozulmalara yol açabileceği için verapamil yerine kısa etkili adenozin tercih edilebilir. Adenozinin yarı ömrü de oldukça kısa (1-10 saniye) ve etkinliği hızlıdır [18]. Ayrıca, sol ventrikül fonksiyonları düşük seviyedeki hastalarda verapamilden kaçınılmalı, bunun dışında, kalp fonksiyonları normal bireylerde bile verapamilin başarısız olması durumunda hemen ardından beta bloker kullanılmasının hemodinamiyi bozabileceği akla gelmelidir. Bir başka kalsiyum kanal blokeri olan diltiazemin verapamilden daha az yan etkisi olması nedeniyle daha güvenle kullanılabileceği düşünülmektedir [19]. AVNRT'nin tedavisinde digoksinin etkinliği tartışmalıdır. $\mathrm{Bu}$ ajanın diğer ilaçlarla etkileşimi, etkisinin geç başlaması ve taşikardi esnasında zaten sempatik tonüs artmış olmasından dolayı akut safhada kullanımı sınırlıdır. AVNRT'nin uzun dönem tedavisinde medikal tedavi kişiselleştirilmelidir. Hasta semptomları tolere edebiliyorsa basit manevraların öğretilmesi yeterli olabilir. 
Fakat ciddi semptomları olan, koroner arter hastaşığı gibi ek hastalıkları olan, nadir de olsa senkop gelişen hastalar ve sik sik acil servise başvuran hastalarda ilaç tedavisi gereklidir. Genellikle, ikili yolak modelinde antegrad yolağı bloke eden ilaçlar ilk seçenektir. Bunlar az önce değindiğimiz kalsiyum kanal blokerleri, beta blokerler, adenozin ve nadiren digoksindir. Retrograd yolağ inhibe eden ajanlar ise genellikle ilk yaklaşım başarısız ise kullanılır: flekainid, propafenon, disopramid ve kinidin. Klas 3 antiaritmikler iki yolağı da inhibe ederler. SVT epizotları nadir olan ve hafif semptomlarla seyreden hastalarda ise hastane dışında antiaritmik ilaç kullanımı için cepte-ilaç (pill-in-pocket) stratejisi izlenebilir. Hastanın sadece semptomlar başladığında propranolol veya diltiazem dozları aldığ bu yöntemde taşikardinin sonlanması ilaç emilimine bağlıdır ve saatlerce ertelenebilir [20]. Medikal tedavide kullanılacak ajan belirlenirken hastanın yaşı, yapısal kalp hastalığ 1 olup olmadığ 1 , aldığ 1 diğer ilaçlarla etkileşimi ve uyumu göz önüne alınmalıdır. Özellikle klas 1 ve 3 antiaritmiklerin proaritmik özellikleri unutulmamalı ve uzun dönem kullanma kararı verilmeden önce fayda-zarar iyi hesaplanmalıdır.

\section{Kateter ablasyon tedavisi:}

Uzun dönem ilaç kullanımının belli bir maliyeti yanında getirmesi ve proaritmik etkileri düşünüldügünde, küratif olması nedeniyle kateter ablasyon tedavisi kimi hastalarda birinci basamak tedavi olarak önerilmektedir. Ablasyon tedavisinde ikili yolağın oluşturduğu devreyi kesintiye uğratmak esastır. Yavaş veya hızlı yolak hedeflenebilir. İlk dönemlerde hızlı yolağın ablasyonu yapılmış ve işlemin \%80-90 başarıya karşın \%20'ye varan AV blok riski taşıması nedeniyle yavaş yolağın ablasyonuna ağırlık verilmiştir [21, 22]. Atriyoventriküler nod; Todaro tendonu, koroner sinüs ostiumu ve triküspit kapak septal yaprakçığının oluşturduğu Koch Üçgeni içinde bulunan bir yapıdır [10, 11]. Koch üçgeni yavaş yol ablasyonu ya da modifikasyonu için hedeflenen bölge olması nedeniyle işlemin daha rahat yapılabilmesi için anatomik olarak inferior, mid ve superior bölgelere hayali olarak ayrılmıştır. Klasik yaklaşım daha çok mid ve superior segmentleri tercih ettiğinden, ablasyon uygulanması sırasında ya da sonrasında kalıcı blok gelişme riski \%1 civarı olarak belirlenmiştir [23]. İşlem başarısı yüksek ve rekürrens oranı düşük olmasına rağmen atriyoventriküler bloktan kaçınma isteği operatörleri daha güvenilir hedef bölgeler aramaya itmiştir. Çalışmada alternatif yaklaşım olarak adlandırdığımız bu yöntemde ise, Koch üçgeninin inferior komşuluğunda çok komponentli atriyal elektrogramların kaydedildiği yerlerin yavaş yolağı temsil ettiği düşüncesiyle hareket edilmiştir [24]. Ancak bu yöntemin blok riski daha düşük olsa da $(\% 0,8)$ nüks oranlarının yüksek olduğu $(\% 6,9)$ bir gerçektir [25].

\section{Kaynaklar}

1. U.S. Department of Health \& Human Services (DHHS): Centers for Disease Control Vital and Health Statistics. National Hospital Discharge Survey: annual summary with detailed diagnosis and procedure data (1999). DHHS Publication No. (PHS) 2001; 2001-1722.

2. Orejarena LA, Vidaillet H Jr, DeStefano F, Nordstrom DL, Vierkant RA, Smith PN, Hayes JJ. Paroxysmal supraventricular tachycardia in the general population. J Am Coll Cardiol 1998; 31: 150-7.

3. Porter MJ, Morton JB, Denman R, Lin AC, Tierney S, Santucci PA, Cai JJ, Madsen N, Wilber DJ. Influence of age and gender on the mechanism of supraventricular tachycardia. Heart Rhythm 2004; 1: 393-6.

4. Mines GR. On dynamic equilibrium in the heart. J Physiol 1913; 46: 349-83.

5. Iliescu CC, Sebastiani A. Notes on the effects of quinidine upon paroxysms of tachycardia. Heart 1923; 10: 223-30.

6. Barker PS, Wilson FN, Johnston FD. The mechanism of auricular paroxysmal tachycardia. Am Heart J 1943; 26: 435-45.

7. Moe GK, Preston JB, Burlington $\mathrm{H}$. Physiologic evidence for a dual A-V transmission system. Circ Res 1956; 4: 357-75. 
8. Mendez C, Moe GK. Demonstration of a dual A-V nodal conduction system in the isolated rabbit heart. Circ Res 1966; 19: 378-93.

9. Goldreyer BN, Bigger JT Jr. Site of reentry in paroxysmal supraventricular tachycardia in man. Circulation 1971; 43: 15-26.

10. Lev M, Widran J, Erickson EE. A method for the histopathologic study of the atrioventricular node, bundle, and branches. AMA Arch Pathol 1951; 52: 73-83.

11. Widran J, Lev M. The dissection of the atrioventricular node, bundle and bundle branches in the human heart. Circulation 1951; 4: 863-7.

12. Anderson RH, Ho SY. The architecture of the sinus node, the atrioventricular conduction axis, and the internodal atrial myocardium. J Cardiovasc Electrophysiol 1998; 9: 1233-48.

13. Wu D, Yeh SJ, Wang CC, Wen MS, Chang HJ, Lin FC. Nature of dual atrioventricular node pathways and the tachycardia circuit as defined by radiofrequency ablation technique. J Am Coll Cardiol 1992; 20: 884-95.

14. Keim S, Werner P, Jazayeri M, Akhtar M, Tchou P. Localization of the fast and slow pathways in atrioventricular nodal reentrant tachycardia by intraoperative ice mapping. Circulation 1992; 86: 919-25.

15. Spach MS, Josephson ME. Initiating reentry: the role of nonuniform anisotropy in small circuits. J Cardiovasc Electrophysiol 1994; 5: 182-209.

16. Waxman MB, Wald RW, Sharma AD, Huerta F, Cameron DA. Vagal techniques for termination of paroxysmal supraventricular tachycardia. Am J Cardiol 1980; 46: 655-64.

17. Waxman MB, Bonet JF, Finley JP, Wald RW. Effects of respiration and posture on paroxysmal supraventricular tachycardia. Circulation 1980; 62: 1011-20.

18. DiMarco JP, Miles W, Akhtar M, Milstein S, Sharma AD, Platia E, McGovern B, Scheinman MM, Govier WC. Adenosine for paroxysmal supraventricular tachycardia: dose ranging and comparison with verapamil. Assessment in placebo-controlled, multicenter trials. The Adenosine for PSVT Study Group. Ann Intern Med 1990; 113: 104-10.

19. Huycke EC, Sung RJ, Dias VC, Milstein S, Hariman RJ, Platia EV. Intravenous diltiazem for termination of reentrant supraventricular tachycardia: a placebocontrolled, randomized, double-blind, multicenter study. J Am Coll Cardiol 1989; 13: 538-44.

20. Yeh SJ, Kou HC, Lin FC, Hung JS, Wu D. Effects of oral diltiazem in paroxysmal supraventricular tachycardia. Am J Cardiol 1983; 52: 271-8.

21. Epstein LM, Scheinman MM, Langberg JJ, Chilson D, Goldberg HR, Griffin JC. Percutaneous catheter modification of the atrioventricular node. A potential cure for atrioventricular nodal reentrant tachycardia. Circulation 1989; 80: 757-68.

22. Jazayeri MR, Hempe SL, Sra JS, Dhala AA, Blanck Z, Deshpande SS, Avitall B, Krum DP, Gilbert CJ, Akhtar M. Selective transcatheter ablation of the fast and slow pathways using radiofrequency energy in patients with atrioventricular nodal reentrant tachycardia. Circulation 1992; 85: 1318-28.

23. Spector P, Reynolds MR, Calkins H, Sondhi M, Xu Y, Martin A, Williams CJ, Sledge I. Meta-analysis of ablation of atrial flutter and supraventricular tachycardia. Am J Cardiol 2009; 104: 671-7.

24. Steven D, Rostock T, Hoffmann BA, Servatius H, Drewitz I, Müllerleile K, Klemm H, Melchert C, Wegscheider K, Meinertz T, Willems S. Favorable outcome using an abbreviated procedure for catheter ablation of AVNRT: results from a prospective randomized trial. J Cardiovasc Electrophysiol 2009; 20: 5225.

25. Clague JR, Dagres N, Kottkamp H, Breithardt G, Borggrefe M. Targeting the slow pathway for atrioventricular nodal reentrant tachycardia: initial results and long-term follow-up in 379 consecutive patients. Eur Heart J 2001; 22: 82-8. 